\title{
Inclusão educacional de pessoas com Autismo no Brasil: uma revisão da literatura
}

\author{
Debora Regina de Paula Nunes* \\ Mariana Queiroz Orrico Azevedo** \\ Carlo Schmidt****
}

\section{Resumo}

A legislação brasileira determina que todas as crianças devem ter acesso à escola comum, incluindo sujeitos com transtornos do espectro do autismo (TEA). Embora um corpo substancial de pesquisas descreva os benefícios derivados da inclusão dessas pessoas, o tema ainda permanece controverso, principalmente quanto à possibilidade das escolas oferecerem respostas adequadas às necessidades de crianças com TEA. O presente artigo tem por objetivo identificar o que as produções científicas nacionais, publicadas entre 2008 e 2013, têm revelado sobre a inclusão de pessoas com TEA no Brasil. Os resultados mostram que a presença desses educandos, em escolas regulares, aumentou de forma expressiva após a popularização do paradigma da inclusão. Por outro lado, observa-se que o desconhecimento sobre a síndrome e a carência de estratégias pedagógicas específicas pode acarretar poucos efeitos na aprendizagem desta população.

Palavras-chave: Transtorno do Espectro do Autismo; Inclusão; Revisão descritiva.

\footnotetext{
* Professora Doutora do Departamento de Fundamentos e Políticas da Educação da Universidade Federal do Rio Grande do Norte, Natal, Rio Grande do Norte, Brasil.

** Pedagoga e Professora especialista de Educação Inclusiva do Instituto Federal de Educação, Ciência e Tecnologia do Rio Grande do Norte, Campus EaD. Natal, Rio Grande do Norte, Brasil.

*** Professor Doutor do Departamento de Educação Especial da Universidade Federal de Santa Maria (UFSM), Santa Maria, Rio Grande do Sul, Brasil.
} 


\title{
Educational inclusion of students with Autism in Brazil: a literature review
}

\begin{abstract}
Brazilian legislation mandates that all children with disabilities have access to general education, including those with autism spectrum disorders (ASD). While the benefits of mainstreamed education have been described in numerous studies, the topic remains controversial, particularly regarding the competence of general schools in addressing the needs of students with ASD. The purpose of this article is to describe what studies published between 2008 and 2013 have revealed about the educational inclusion of people with ASD in Brazil. The results indicate that the access of these students to regular classrooms increased after the popularization of the inclusion paradigm. In spite of this fact, investigations suggest that school personnel have scarce knowledge concerning the syndrome and the educational strategies applied in schools may entail little effect on the learning process of these students.
\end{abstract}

Keywords: Autism Spectrum Disorder; Inclusion; Descriptive review

Introdução

O Transtorno Autista é uma condição classificada no DSM-5 como pertencente à categoria denominada Transtornos de Neurodesenvolvimento, recebendo o nome de Transtornos do Espectro Autista (TEA). Assim, o TEA é definido como um distúrbio do desenvolvimento neurológico, que deve estar presente desde a infância, apresentando déficits nas dimensões sociocomunicativa e comportamental (APA, 2013).

Estas características podem favorecer o isolamento da criança, empobrecendo, ainda mais, suas habilidades comunicativas, ao que a literatura é unânime em indicar diagnóstico e intervenção precoces (BRASIL, 2013). Nesse sentido, a escola se constitui como um recurso fundamental para enriquecer as experiências sociais das crianças com TEA, oportunizando a interação entre pares e contribuindo para o desenvolvimento de novas aprendizagens e comportamentos.

A inclusão educacional escolar, no Brasil, é uma ação política, cultural, social e pedagógica que visa garantir o direito de todos os alunos de estarem juntos, aprendendo e participando (BRASIL, 2007). A Educação Especial vem sendo discutida no Brasil a partir da Declaração Universal dos Direitos Humanos, em 1948. Mas, apesar da Lei de Diretrizes e Bases da Educação Nacional propor que as pessoas com deficiência deveriam ser inseridas, preferencialmente, no ensino regular, foi apenas a partir da Constituição de 1988 e sob a influência da Declaração de Jomtien (1990) e da Declaração de Salamanca (1994), que, em nosso país, começou a ser discutida a universalização da Educação, e a ser implementada nas escolas regulares uma política de Educação Inclusiva, culminando com a Política Nacional de Educação Especial na perspectiva da Educação Inclusiva (2008). 
A Política Nacional de Educação Especial na Perspectiva da Educação Inclusiva (2008) determina que os alunos com TEA, assim como aqueles com deficiência e altas habilidades/superdotação, devem estar incluídos na rede regular de ensino, recebendo Atendimento Educacional Especializado (AEE) no contraturno.

O AEE tem como função identificar, elaborar e organizar recursos pedagógicos e de acessibilidade que eliminem as barreiras para a plena participação dos alunos nas escolas públicas e privadas, considerando suas necessidades específicas. As atividades desenvolvidas por esses educandos nas salas do AEE devem diferenciarse daquelas realizadas na sala comum, não sendo substitutivas à escolarização, mas sim complementar e/ou suplementar ao processo de aprendizagem dos alunos.

As ações governamentais, incontestavelmente, ampliaram o ingresso de educandos com autismo em classes comuns após o advento da política de 2008. Dados do Censo Escolar do Ministério da Educação, por exemplo, indicam que, em 2006, havia 2.204 alunos com esse diagnóstico inseridos em escolas regulares; em 2012, esse número aumentou para 25.624. Neste cenário, é imprescindível avaliar os aspectos qualitativos desse acesso. Assim, o presente artigo tem como objetivo descrever a escolarização de pessoas com TEA em escolas regulares, tendo como base a produção científica nacional dos últimos cinco anos.

\section{Metodologia}

A revisão bibliográfica foi operacionalizada mediante a busca eletrônica de artigos, teses e dissertaçoes publicados entre 2008 e 2012, nas bases de dados SciELO, Bireme e Capes. O refinamento de pesquisa constituiu-se pela busca de descritoreschaves, incluindo os termos autismo associado à inclusão escolar, educação especial, escolarização, sala de aula regular e/ou professores/educadores. Foram considerados apenas os trabalhos publicados na íntegra, que tivessem como foco o processo de escolarização de alunos com TEA em classes comuns. No total, foram analisadas, de forma descritiva, 28 produções.

\section{Resultados}

Pesquisas conduzidas em diferentes estados brasileiros descrevem o impacto da Política Nacional de Educação Especial (2008) na escolarização de educandos com autismo (SERRA, 2008; CRUZ, 2009; LAZZERI, 2010; FRANCESCHI, 2012; GOES, 2012). Apesar do laudável intuito de viabilizar o acesso ao ensino regular, as ações governamentais respaldadas na política têm gerado, por vezes, práticas contraditórias e segregadoras. A nova legislação tensiona a relação entre as escolas regulares e especiais, como sugeriu a pesquisa de Franceschi (2012). A autora descreveu o caso da Secretaria de Educação de um município paulista que propôs, após a publicação da nova política, ações para viabilizar o acesso de alunos com deficiência em escolas regulares e manter, simultaneamente, uma escola especial para estudantes com autismo. A pesquisa revelou que muitos profissionais dessa instituição sentiam-se ameaçados com a inclusão dos alunos em escolas regulares, temendo o fechamento da escola especial. Adicionalmente, segundo a autora, o 
método TEACCH, empregado nessa instituição, era contrário à escolarização da pessoa com autismo em classes regulares. Este fato gerava tensões com a Secretaria que, em consonância com a política, visava incluir os educandos com autismo nas escolas regulares.

Serra (2008), por sua vez, observou a presença de um continuum de serviços de atendimento para educandos com autismo em dois municípios fluminenses. Esse modelo educacional era dividido em quatro modalidades de ensino: classes especiais, salas de recursos, preparação para a inclusão e salas regulares. Neste modelo, o grau de severidade da síndrome era determinante para a inserção do educando em contextos mais ou menos segregados. A fragilidade desse sistema foi revelada em entrevistas conduzidas com professores, pais e alunos das escolas que, apoiados nas políticas que fundamentam as práticas pedagógicas, os professores mostraram-se favoráveis à inclusão de alunos com autismo, adotando esta como palavra de ordem. Por outro lado, foram identificadas barreiras que dificultavam esse processo, como a escassa rede de apoio, pouca formação específica dos professores e presença de atitudes segregacionistas dos colegas, gerando insegurança nos pais dos alunos incluídos.

O estudo de Goes (2012), também identificou insegurança dos pais de alunos incluídos, o que conduziu à evasão da escola comum e ao retorno para escolas especiais, em municípios paulistanos. Tal movimento foi descrito pelos autores como impulsionado pelas dificuldades dessas escolas em atender às especificidades educacionais dos alunos com autismo. Neste cenário, as escolas especiais eram percebidas pelos pais de filhos com autismo como espaços que forneciam mais segurança e oferta de serviços educacionais aos alunos com deficiência, de maneira a integrá-los no ambiente escolar. Embora fossem favoráveis à educação inclusiva, muitos revelaram que seus filhos tiveram matrículas negadas em instituições regulares de ensino no Distrito Federal, devido ao preconceito dos professores e gestores da escola comum (Goes, 2012).

Matricular um filho com autismo em uma classe especial, no entanto, não é possível em alguns municípios brasileiros. Em consonância com a nova política, por exemplo, as classes especiais foram extintas no município de Santa Maria/RS. De acordo com Lazzeri (2010), os alunos dessas instituições foram inseridos em escolas comuns e passaram a receber, em turno inverso, o atendimento educacional especializado (AEE). Embora a matrícula tenha sido garantida pela nova política, a permanência desses educandos nas classes, regulares é questionável. Lazzeri (2010) constatou que muitos alunos de Santa Maria, com autismo, foram posteriormente remanejados para classes especiais do estado. Nesse sentido, Lazzeri (2010) alerta que, dependendo da severidade da síndrome, um atendimento individualizado não pode ser ofertado na escola regular. Assim, há de se pensar em um modelo díspar do preconizado pela atual política nacional, envolvendo profissionais especializados (LAZZERI, 2010).

Em consonância com Lazerri (2010), Serra (2008) alerta para a necessidade de uma reformulação das políticas públicas de educação para garantir não somente o acesso, mas também a permanência dos alunos com autismo na escola comum, 
conforme preconizado pela Lei no 12.764, de 27 de dezembro de 2012. A permanência desse aluno pode ser viabilizada, por exemplo, pela presença de um acompanhante especializado, que mediaria o trabalho de inclusão. A presença desse agente, prevista na supracitada lei, pode favorecer o processo de inclusão de educandos com autismo, como sugerem os estudos de Giardinetto (2009) e Parra (2009).

A necessidade de uma adequada formação desses profissionais é salientada por Gomes e Mendes (2010). O estudo conduzido pelas autoras mostrou que $80 \%$ dos professores de apoio de escolas municipais de Belo Horizonte eram estudantes de segundo grau, sem formação específica na área da Educação Especial. A falta de formação e a ausência de supervisão podem fazer com que esse professor perca suas funções educacionais, exercendo apenas o papel de cuidador (GOMES; MENDES, 2010, p. 392).

Giardinetto (2009) enfatiza a importância de um modelo colaborativo de trabalho, operacionalizado por agentes da escola comum e especial. Em sua pesquisa, descreve os resultados promissores de quatro alunos com autismo que frequentavam, simultaneamente, a escola regular e especial. Neste trabalho, a autora ressalta a importância do professor auxiliar como mediador no processo de inclusão na educação infantil e fundamental. Constata, ainda, que em séries mais avançadas, a demanda por orientações de profissionais especialistas tende a ser maior do que na educação infantil.

Parra (2009), por sua vez, discute a importância do Acompanhante Terapêutico (AT) como forma de auxiliar no processo de inclusão de educandos com autismo. AT é uma modalidade de atendimento que, apesar de ser oriunda da clínica, pode extrapolar esse ambiente. De forma específica, caracteriza-se pelos serviços de um profissional que se disponibiliza a estar junto à pessoa com necessidades específicas em suas atividades cotidianas com a proposta de promover sua autonomia e independência e (re)inserí-la no convívio social. Nesse sentido, este papel se assemelha ao do professor auxiliar descrito por Giardinetto (2009). Ele pode favorecer a inclusão, atuando junto à criança que ainda não se encontra adaptada ao universo escolar, e, com a qual, o corpo docente acredita não saber lidar (PARRA, 2009). A autora destaca que: somente a presença deste profissional nas escolas não seria suficiente para garantir a permanência dos alunos na instituição. Assim, salienta a necessidade de articular sua prática com as do professor regente e demais membros da instituição. Tal articulação poderia auxiliar o professor regente a melhor compreender esses alunos, inclusive, contribuindo para que esse entenda, de forma mais adequada, o autismo e seus desafios, minimizando o impacto negativo da sua pouca formação específica.

O papel de um agente mediador, na relação do aluno com autismo com seus pares, e o valor terapêutico da escola são, também, discutidos no estudo de Dantas (2009). No contexto da escola inclusiva, a autora ressalta a necessidade de o docente manejar a função educativa e constitutiva do aluno com autismo. A partir de uma perspectiva psicanalítica, argumenta que a tarefa do professor deve extrapolar a objetividade pedagógica. Neste cenário, descreve a relação transferencial 
de um menino com autismo (5 anos) e sua professora. Salienta, nessa discussão, a importância de o professor "traduzir" os comportamentos do aluno com prejuízos na comunicação para seus interlocutores na escola.

Partindo do pressuposto de que os alunos com autismo estão sendo inseridos em classes comuns, de maneira abrupta ou gradua, que modelos teóricos norteiam as práticas dos docentes que atuam com essa população? Esta questão foi abordada nos estudos de Prestes (2009) e Braga (2009). Na primeira investigação, Prestes (2009) analisou os relatórios psicopedagógicos e a anamnese de 30 alunos com autismo, matriculados na rede regular de ensino do Distrito Federal. Os documentos revelaram que a teoria predominante que orienta as práticas dos professores é a cognitiva-comportamental. Os resultados indicaram, que a maioria dos diagnósticos realizados na rede é expedida por psiquiatras, o que exclui a escuta da família e do sujeito. Assim, a avaliação psicopedagógica deixa de executar seu papel terapêutico e de orientação aos pais e professores no processo de inclusão escolar dos alunos.

Braga (2009), por sua vez, investigou as concepções de aprendizagem e desenvolvimento de 15 professores que trabalhavam com crianças com autismo, em escolas comuns, especiais e instituições especializadas do Distrito Federal. A autora verificou, ainda, se tais concepções interferiam nas práticas pedagógicas adotadas em sala de aula. Com base na coleta de dados, foi evidenciada pouca relação entre as concepções teóricas dos professores e suas práticas. Em geral, prevaleciam concepções de desenvolvimento, aportadas na abordagem histórico-cultural e o uso de estratégias de ensino derivadas do modelo behaviorista. A autora propõe que os professores se ancoram na abordagem comportamental em razão da incipiência de estratégias de ensino empiricamente validadas para essa população. Esse argumento deve ser analisado com cautela, uma vez que a literatura internacional dispõe de estudos que sinalizam práticas cientificamente validadas para educandos com autismo (SIMPSON, 2005). Poucas, no entanto, são empregadas pelos professores nas salas de aula regulares (HESS et al., 2008). No Brasil, pressupõe-se que essas estratégias sejam pouco conhecidas e investigadas. Talvez seja esse um dos motivos pelos quais a produção nacional revele que os métodos de ensino utilizados pelos professores produzem limitado impacto na aprendizagem dos educandos com autismo (NUNES, 2012).

Os resultados das pesquisas conduzidas por Gomes e Mendes (2010), Cruz (2009), Nunes e Lemos (2009) e Pedrosa (2010) alicerçam essa hipótese. No primeiro estudo, Gomes e Mendes (2010) investigaram o processo de escolarização de 33 educandos com autismo em escolas municipais regulares de Belo Horizonte. Os resultados da investigação indicaram que em torno de 90\% desses alunos não acompanhavam os conteúdos pedagógicos desenvolvidos pelas escolas. Uma parcela expressiva dos educandos do $2^{\circ}$ e $3^{\circ}$ ciclos do ensino fundamental não sabia ler, escrever ou fazer contas. Adicionalmente, os dados revelaram que no $1^{\circ}, 2^{\circ}$ e $3^{\circ}$ ciclos, em torno de $40 \%$ dos alunos com autismo estavam em etapas que não correspondiam à idade cronológica esperada. 
Cruz (2009), por sua vez, analisou a experiência escolar de dois adolescentes autistas em escolas regulares da rede pública municipal paulista. A autora constatou que as práticas pedagógicas adotadas não favoreciam a apropriação de conteúdos escolares. Em geral, as tarefas realizadas pelos jovens que tinham, respectivamente, 16 e 19 anos, se limitavam a meras cópias, atividades repetitivas e, por vezes, de caráter infantilizador.

Nunes e Lemos (2009) e Pedrosa (2010) focaram na escolarização de alunos com autismo no contexto da educação infantil. No primeiro estudo, o cotidiano de um menino de 5 anos, com autismo e características de hiperlexia, inserido em uma escola regular na cidade de Natal - RN, foi investigado. Assim, como no estudo de Cruz (2009), as autoras observaram que a criança passava a maior parte do tempo engajada em atividades isoladas e repetitivas. Nesta investigação, não foram observadas adaptações curriculares que pudessem favorecer o acesso do educando ao currículo da educação infantil.

O objetivo do estudo de Pedrosa (2010) foi analisar as interações de uma criança com autismo (5 anos) com seus colegas, com sua professora e demais funcionários da escola. Os resultados indicaram que o aluno parecia satisfeito em seu contexto escolar. Era aceito por seus pares e professora, e estabelecia com eles interações positivas. A docente empenhava-se em estimular comportamentos de autonomia no aluno, mas, corroborando o apresentado em outros estudos, também se queixava por desconhecer as especificidades do autismo. Registros indicaram, ainda, o preconceito e a discriminação expostos por funcionários que interagiam com o aluno nos diferentes espaços da escola. Pedrosa (2010) ressalta a necessidade da equipe técnica da escola participar de cursos de capacitação para a inclusão, conhecer as especificidades dos alunos com deficiência, assim como os recursos pedagógicos que viabilizam sua aprendizagem.

Desse modo, a precariedade na formação de professores representa uma importante barreira na efetivação da proposta de inclusão escolar (GLAT; PLETSCH, 2011). Assim, para que uma escola atenda adequadamente as necessidades educacionais de seus alunos, é necessária a formação inicial e continuada que contemple a tríade reflexão-ação-crítica, dos professores envolvidos diretamente nesse processo. Ou seja, no paradigma do professor reflexivo e crítico, a prática deixa de ser um campo de aplicação para se tornar um campo de investigação, através de um contato maior com a realidade escolar. Para tanto, é necessário um trabalho colaborativo, dando ênfase ao conhecimento de toda a comunidade escolar visando à construção de conhecimentos, às trocas de experiências e às práticas educativas inclusivas transformadoras (VITALIANO; VALENTE, 2010).

Contudo, a refratária política da Educação Especial tem delegado ao professor a responsabilidade de criar, de forma isolada, condições necessárias ao atendimento e à escolarização de educandos em situação de deficiência (CRUZ, 2009; FONSECA, 2009). Nesse sentido, ter um aluno com autismo é percebido como um "desafio", que instiga o docente a, sozinho, investir em uma formação profissional continuada. Esses resultados foram encontrados no estudo de Fonseca 
(2009) que, por meio de uma narrativa autobiográfica, descreveu a constituição da identidade profissional de uma professora que atuava há onze anos com alunos com autismo. O incansável empenho da docente em atender às necessidades educacionais de seus alunos é descrito na dissertação. De acordo com o relato, as incongruências e demandas do sistema educacional suscitaram sentimentos de impotência e desequilíbrio emocional na professora, afetando sua identidade pessoal e profissional.

Por que o autismo seria, na perspectiva da professora investigada por Fonseca (2009), um "desafio"? Que concepções os professores têm sobre essa síndrome? As percepções dos educadores sobre o autismo foi tema dos estudos desenvolvidos por Santos (2009) e Gomide (2009). No primeiro trabalho, Santos (2009) investigou, através do referencial da teoria das representações sociais, as ideias de senso comum - que circulam entre professores com e sem experiência na educação de autistas - a respeito do autismo.

O desconhecimento e a incerteza a respeito da origem da síndrome foram respostas prevalentes entre os professores sem experiência. Estes docentes pensavam no autista como um ser encapsulado em um mundo interno, rico em imaginação. Os professores experientes, por sua vez, ressaltavam o agravamento dos sintomas autísticos à medida em que a idade avançava e um futuro com poucas possibilidades de inserção social. Em geral, ligavam o autismo a imagens de um mundo vazio, sem atividade inteligente, ou com uma memória "enciclopédica" e pouco funcional. Como argumenta Santos (2009), esses sentimentos podem refrear o nível de empatia em relação ao aluno com autismo, prejudicando a interação social e o próprio trabalho pedagógico desenvolvido com esse educando.

De fato, Gomide (2009) observou que as baixas expectativas, em relação às potencialidades dessa população, impactam a prática do professor. Neste estudo, a autora analisou aspectos psicoeducacionais relacionados ao atendimento escolar de alunos com autismo, e a relação destes aspectos com a promoção do desenvolvimento global destes educandos. Dados observacionais e entrevistas com quatro professores de escolas regulares e especiais revelaram a percepção exacerbada das limitações e dificuldades das pessoas com autismo em termos emocionais e cognitivos. A visão psicopatologizante e a falta de informações sobre, as possibilidades de aprendizagem desses educandos, afetavam o trabalho pedagógico proposto pelos professores. Assim, a prática desses educadores era marcada pela predominância de tarefas relacionadas às Atividades da Vida Diária (AVDs) e a carência de atividades pedagógicas, como a matemática, a leitura e a escrita.

Os estudos de Santos (2009) e Gomide (2009) alertam para as concepções negativas que os educadores podem ter em relação aos alunos com autismo. Este fenômeno pode advir da própria mídia, como salienta Schmidt (2012). Este autor realiza uma análise da concepção de autismo a partir da produção midiática e bibliográfica recentes. Dentre as conclusões, mostra que há importantes distorções na forma como o autismo é apresentado, ora sendo concebido como uma pessoa isolada e refratária à interação, ora como dotado de habilidades especiais e surpreendentes. Tais imagens caricaturais contribuem para a formação de crenças, explicações e ideias 
sobre o autismo, o que se relaciona ao conceito de representação social da síndrome apresentada no estudo de Santos (2009).

Como se configuram as interações do educando com autismo com seus pares e agentes da escola? Essa questão de pesquisa foi abordada por Brandão (2009), Marocco (2012) e Rhame (2010). No primeiro estudo, Brandão (2009) analisou as interações sociais de um menino com autismo, de 8 ano, com seus colegas e professores em uma escola regular e uma Escola Parque. ${ }^{1}$ Os tipos de tarefas realizadas na escola regular demarcavam a diferença de ritmo de desenvolvimento do aluno em relação aos seus colegas e tendiam a limitar suas interações sociais. Esse fato parecia estar relacionado ao apoio individualizado ofertado pela professora. Ou seja, com o objetivo de progredir na aprendizagem de atividades de leitura e escrita, o aluno utilizava um material didático pessoal e era orientado, de forma individualizada, pela docente. Por outro lado, na Escola Parque, o aluno se igualava aos colegas na realização das atividades que ocorriam, em geral, de forma coletiva. A autora conjectura que a falta de um conteúdo formal, como a aprendizagem da leitura e escrita, garantia mais liberdade ao professor da Escola Parque na realização das atividades. As tarefas feitas em grupo e o compartilhamento do material didático favoreciam as interações do aluno com seus pares. O estudo sinaliza a importância do contexto sobre a qualidade, a estrutura e o estilo comportamental de interação da criança com autismo.

Já Marrocco (2012) realizou entrevistas semiestruturadas com duas professoras (uma da escola regular e outra do Atendimento Educacional Especializado), profissionais e famílias dos sujeitos envolvidos, bem como utilizou-se das observações e dos diários de campo para registrar os modos de interação de seis sujeitos com autismo (quatro crianças e dois adolescentes) com seus profissionais e famílias em busca de perceber e analisar os comportamentos interativos entre esses sujeitos. Com o intuito de reunir diversos elementos para compreender essas interações, retratou diferentes momentos da vida desses sujeitos nas relações e linguagens (oral, gestual) nos episódios interativos. Nesta perspectiva, o contexto da pesquisa na área da educação se move potencializando as múltiplas linguagens, o conhecer e os modos de interação como formas do movimento humano, como um autoproduzir-se. Os resultados das entrevistas mostraram que a comunicação tem um viés a ser desenvolvido nas relações e que as ações dos profissionais da Educação em apostar nas trajetórias escolares de sujeitos com autismo são, ainda, pontos de muita tensão, já que a interação é algo a ser pensado nos processos educativos, partindo das relações que ela pode estabelecer.

Nessa mesma perspectiva, Rhame (2010) investigou o laço social (interação social) de alunos com autismo no contexto educacional. O foco da pesquisa foi a convivência desses educandos com seus colegas em contextos ditos inclusivos. As análises indicaram possíveis desdobramentos desse "estar-junto", sinalizando os efeitos que o aluno autista provocava nos colegas de sua sala de aula, bem como nos das outras salas. No plano micro, o estudo revelou a existência de operações ligadas à constituição de laços entre as crianças, como os saberes da 
experiência. Adicionalmente, foram observados efeitos terapêuticos positivos no processo de inserção do educando com autismo na escola comum. A pesquisa trouxe, como conclusão, a necessidade de implementar políticas públicas em um plano micro, considerando a convivência entre os alunos. Na vertente macro, a autora discutiu os constantes impasses presentes na abordagem do indivíduo na educação em contextos inclusivos, visto que a busca pela homogeneização e padronização comportamental e social, via educação escolar, é um desafio nos movimentos atuais por uma educação para todos. Portanto, o estudo expressou tanto os movimentos acolhedores e de admiração dos colegas em relação ao aluno autista, quanto os momentos de tensão dos laços e de nomeação de sua suposta diferença.

Alguns estudos têm descrito estratégias que parecem viabilizar o acesso desses educandos ao currículo regular (GIARDINETTO, 2009; GOMIDE, 2009; BEZ, 2010; MELO, 2010; GOMES, 2011 BRANDIZZI, 2009).

Giardinetto (2009), por exemplo, descreve as contribuições do programa Currículo Funcional Natural $(\mathrm{CFN})^{2}$ na inclusão de alunos do ensino infantil e fundamental. Seu estudo se alicerça no modelo ecológico em Educação Especial, tendo como foco as interações estabelecidas entre a pessoa e seus diferentes grupos sociais. O CFN se fundamenta em planejar um programa de educação que seja vital e útil para o indivíduo e, assim, contribuir para que o sujeito com autismo participe ativamente, de forma independente, produtiva e socialmente aceitável, das atividades realizadas no contexto familiar, educacional e social (CUCCOVIA, 2003; GIARDINETTO, 2009; SUPLINO, 2009).

Brandizzi(2009)destacouque, embora subutilizado, orelatóriode avaliação psicopedagógico ${ }^{3}$ é de grande importância na estruturação das ações pedagógicas do professor. Sua pesquisa envolveu 16 docentes da rede pública de ensino do Distrito Federal que atuavam com alunos autistas. De acordo com esses professores, para viabilizar a inclusão os relatórios deveriam ser atualizados com frequência, fornecer informações mais detalhadas sobre a dinâmica de desenvolvimento do aluno ao longo do processo de escolarização, bem como ter o envolvimento do professor no processo de avaliação do aluno.

A importância do relatório psicopedagógico foi, também, salientada no estudo de Prestes (2009), previamente descrito. Neste trabalho, a autora relata que os relatórios de avaliação diagnósticas de alunos com autismo, matriculados na rede pública de ensino do Distrito Federal, falhavam em fornecer informações importantes para a prática pedagógica do professor por utilizarem manuais padronizados (DSM IV-TR e CID-10). A anamnese, por sua vez, era realizada com os pais e se restringia a coletar dados da história de vida do aluno e não sua interação com a família. Os relatórios destacaram, ainda, que a maioria dos alunos utilizava medicamentos, e que poucas crianças estavam incluídas no ensino regular.

Assim como os relatórios psicopedagógicos, os planos de ensino podem se configurar como instrumentos de grande valia no processo de escolarização do 
autista. Melo (2010), por exemplo, ressalta a importância dos planos de ensino em um estudo que visava desvelar as percepções de professores sobre estratégias pedagógicas implementadas com educandos com autismo. O estudo, de caráter etnográfico, envolveu 376 professores e foi realizado por meio da elaboração coletiva de cem planos de aula. Os resultados indicaram que quando professores pensam as estratégias pedagógicas de sala de aula, considerando as peculiaridades do desenvolvimento do autista, tornam-se capazes de planejar e atingir objetivos mais claros, que darão sentido ao objeto de conhecimento, tornando o processo de aprendizagem mais motivador.

O emprego de Tecnologias Assistivas (TA), com essa população, tem, também, evidenciado resultados positivos, como revelam as pesquisas de Bez (2010) e Gomes (2011). No estudo de Bez (2010), ações mediadoras foram implementadas utilizando recursos de TA com um aluno de 7 anos, com autismo. Nas intervenções foram utilizados materiais concretos, sistemas de Comunicação Alternativa e Ampliada (CAA) de baixa tecnologia e Tecnologia da Informação e Comunicação (TIC) para desenvolver a comunicação do aluno. Embora a oralidade do educando tenha se desenvolvido de forma atípica, progressos em sua intencionalidade comunicativa foram registrados após a introdução dos referidos recursos.

O objetivo do trabalho de Gomes (2011) foi avaliar os efeitos de um programa de intervenção nas interações comunicativas entre um aluno com autismo (10 anos) e sua professora. No estudo, a docente foi capacitada a usar um sistema de comunicação de baixa tecnologia com o aluno durante três rotinas da sala de aula. Por meio de um delineamento de pesquisa, quase experimental, foi observado aumento na frequência de interações do aluno, empregando os pictogramas em uma das rotinas investigadas.

\section{Conclusões}

Diante dos estudos analisados constatou-se que a presença de alunos com autismo, em escolas regulares, aumentou de forma expressiva, após a popularização do paradigma da inclusão e, consequente, extinção das escolas especiais. Sobre este aspecto é importante destacar que a inclusão não precisa ser compreendida como uma dicotomia entre inclusão/exclusão, classes especiais ou salas regulares.

Alguns estudos mostram a presença de um continuum de serviços intermediários entre um contexto e outro que permite essas transições ocorrem de modo gradual, como por exemplo, no estudo de Serra (2008). Embora os preceitos do paradigma inclusivo sejam acatados pelas famílias e agentes da escola, o sentimento de desconfiança em relação à sua efetivação é revelado no discurso de alguns pais e professores desses alunos. Em geral, os docentes revelam desconhecer a síndrome e as estratégias pedagógicas para usar em sala de aula. Como resultado, algumas pesquisas indicam que as práticas educacionais adotadas têm produzido poucos efeitos na aprendizagem do aluno autista. 
Alguns estudos descritos no presente artigo tratam dos efeitos promissores do modelo colaborativo de trabalho, coligando as ações de professores regulares e especialistas, como é previsto nas ações políticas para favorecer a escolarização dos educandos.

Recursos de Tecnologia Assistiva, adaptações curriculares e a criteriosa elaboração dos relatórios de avaliação despontam como práticas promissoras no processo de escolarização. Salienta-se, ainda, o uso de planos de ensino capazes de atender às demandas educacionais dos alunos com autismo. Assim, ganha notoriedade o uso do Plano de Ensino Individualizado (PEI), descrito como uma ferramenta de trabalho que norteia as ações pedagógicas do professor e das atividades escolares do aluno. Nesse instrumento, elaborado por equipe multidisciplinar e revisado anualmente, constam informações como as metas de curto e longo prazos que refletem a inclusão do aluno no currículo regular; a forma como o programa educacional será modificado; a maneira como o educando será avaliado; e de que modo participará de atividades extracurriculares (SMITH, 2008).

\section{Referências}

AMERICAN PSYCHIATRIC ASSOCIATION: DSM-IV-TR. Associação Americana de Psiquiatria. DSM-IV-TR - Manual diagnóstico e estatístico de transtornos mentais, 2002.

AMERICAN PSYCHIATRIC ASSOCIATION: DSM-5. Associação Americana de Psiquiatria. DSM-V - Manual diagnóstico e estatístico de transtornos mentais, 2013.

BEZ, M. R. Comunicação aumentativa e alternativa para sujeitos com Transtornos Globais do Desenvolvimento na promoção da expressão e intencionalidade por meio de ações mediadoras. Dissertação (Mestrado em Educação). Programa de Pós-graduação em Educação da Faculdade de Educação da Universidade Federal do Rio Grande do Sul, Porto Alegre - RS, 2010.

BRAGA, I. S. Teorizando as práticas de atendimento à pessoa com autismo na rede de escolas públicas do Distrito Federal. Dissertação (Mestrado em Psicologia). Programa de Pós-graduação em Psicologia da Universidade Católica de Brasília, Brasília - DF, 2009.

BRANDÃO, L. de C. Interação social em diferentes contextos escolares: estudo de caso de uma criança com autismo. Dissertação (Mestrado em Psicologia). Programa de Pós-graduação em Psicologia da Universidade Católica de Brasília, Brasília - DF, 2009.

BRANDIZZI, K. C. L. O papel do relatório psicopedagógico na educação de alunos com autismo. Dissertação (Mestrado em Psicologia). Universidade Católica de Brasília, Brasília DF, 2009.

BRASIL. Declaração Mundial sobre Educação para Todos: plano de ação para satisfazer as necessidades básicas de aprendizagem. UNESCO, Jomtiem/Tailândia, 1990.

Declaração de Salamanca e linha de ação sobre necessidades educativas especiais. Brasília: UNESCO, 1994. 
BRASIL. Ministério da Educação. Plano de Desenvolvimento da Educação: razões, princípios e programas. Brasília: MEC, 2007.

Decreto 7.611, de 17 de nov. de 2011. Dispõe sobre a educação especial, o atendimento educacional especializado e dá outras providências. Disponível em: ‘http://www.planalto.gov. br/ccivil_03/_Ato2011-2014/2011/Decreto/D7611.htm>. Acesso em: 27 maio 2013.

Ministério da Educação. Secretaria de Educação Especial. Política Nacional de Educação Especial na Perspectiva da Educação Inclusiva. Brasília, 2008a. Disponível em: 〈www.mec.gov.br〉. Acesso em: 27 maio 2013.

Ministério da Saúde. Secretaria de Atenção à Saúde. Departamento de Ações Programáticas Estratégicas. Diretrizes de Atenção à Reabilitação da Pessoa com Transtornos do Espectro do Autismo / Ministério da Saúde, Secretaria de Atenção à Saúde, Departamento de Ações Programáticas Estratégicas. Brasília: Ministério da Saúde, 2013. Disponível em: 〈http://portal.saude.gov.br/portal/arquivos/pdf/dir_tea.pdf. Acesso em: 28 de maio 2013.

COUNCIL for Exceptional Children. What every special educator must know: Ethics, standards, and guidelines. 6⿳a ed. Arlington, VA: Author, 2009. Disponível em: < http://www. cec.sped.org///media/Files/Standards/News\%20and\%20Reports/Redbook\%202009.pdf>. Acesso em: 27 maio 2013.

CRUZ, T. S. U. R. da. Acompanhamento da experiência escolar de adolescentes autistas no ensino regular. Dissertação (Mestrado em Educação) - Faculdade de Ciências Humanas Universidade Metodista de Piracicaba. Piracicaba: 2009.

CUCCOVIA, M. M. Análise de procedimentos para avaliação de interesses baseados em um currículo funcional natural e seus efeitos no funcionamento geral de indivíduos com deficiência mental e autismo. Dissertação (Mestrado em Educação Especial) - Universidade Federal de São Carlos, São Carlos, 2003.

DANTAS, A. P. Entre o educar e o constituir: efeitos possíveis da educação de uma criança com transtorno grave de desenvolvimento. Dissertação (Mestrado em Psicologia Clínica). PUC - São Paulo, 2009.

FÁVERO, E. A.; PANTOJA, L. M.; MANTOAN, M.T. Atendimento educacional especializado: aspectos legais e orientação pedagógica. Brasília: MEC/SEESP, 2007.

FONSECA, H. V. História de vida de uma professora de alunos com autismo: constituição da identidade profissional. Dissertação (Mestrado em Educação) - Universidade Católica de Brasília, 2009.

FRANCESCHI, F. Cartografias do encontro da escola com o autismo. Dissertação (Mestrado em Psicologia clínica). PUC - São Paulo, 2012

GIARDINETTO, A. Educação do aluno com autismo: um estudo circunstanciado da experiência escolar inclusiva e as contribuições do currículo funcional natural. 2009. Tese (Doutorado em Educação) - Programa de Pós-Graduação em Educação da Faculdade de Filosofia e Ciências da Universidade Estadual Paulista, Marília, 2009. Disponível em: 〈http:// www.athena.biblioteca.unesp.br/exlibris/bd/bma/33004110040P5/2009/giardinetto_arsb_dr_ mar.pdf>. Acesso em: 27 maio 2013.

Revista Educação Especial | v. 26 | n. 47 | p. 557-572 | set./dez. 2013

Santa Maria 
GLAT, R.; PLETSCH, M. D. Inclusão escolar de alunos com necessidades especiais. Rio de Janeiro: EDUERJ, 2011.

GOES, R. S. A escola de educação especial: uma escolha para crianças autistas e com deficiência intelectual associada de 0 a 5 anos. Dissertação (Mestrado em Psicologia Escolar e do Desenvolvimento Humano) Instituto de Psicologia, Universidade de São Paulo, São Paulo, 2012.

GOMES, C. G. S.; MENDES, E. G. Escolarização inclusiva de alunos com autismo na rede municipal de ensino de Belo Horizonte. Revista Brasileira de Educação Especial, v. 16, n. 3, p. 375-396, 2010. Disponível em: 〈 http://www.scielo.br/pdf/rbee/vl6n3/vl6n3a05.pdf 〉. Acesso em: 27 maio 2013.

GOMES, R. C. Interações comunicativas entre uma professora e um aluno com transtorno invasivo do desenvolvimento na escola regular. Dissertação (Mestrado em Educação). Universidade Federal do Rio Grande do Norte, 2011.

GOMIDE, A. B. A promoção do desenvolvimento do aluno autista nos processos educacionais. 2009. Dissertação (Mestrado em Educação) - Universidade Federal de Uberlândia, Uberlândia, 2009.

HESS, K. L., MORRIER, M. J., HEFLIN, L. J., IVEY, M. L. Autism treatment survey: Services received by children with autism spectrum disorders in public school classrooms. Journal of Autism and Developmental Disorders, v. 38, p. 961-971, 2008. Disponível em: < http://link. springer.com/article/10.1007/s10803-007-0470-5/fulltext.html >. Acesso em: 27 maio 2013.

LAZZERI, C. Educação inclusiva para alunos com autismo e psicose: das políticas educacionais ao sistema de ensino. 2010. 111 fl. Dissertação (Mestrado em Educação), Programa de Pós-Graduação em Educação, Universidade de Federal de Santa Maria, 2010. Disponível em: 〈 http://cascavel.cpd.ufsm.br/tede/tde_busca/arquivo.php?codArquivo=3208 〉. Acesso em: 27 maio 2013.

MAROCCO, V. Sujeitos com autismo em relações: educação e modos de interação. Dissertação (Mestrado em Educação). Universidade Federal do Rio Grande do Sul. Faculdade de Educação. Programa de Pós-Graduação em Educação, 2012.

MELO, S. C. Inclusão em Educação: um estudo sobre as percepções de professores da rede Estadual de Ensino Fundamental do Rio de Janeiro, sobre práticas pedagógicas de inclusão. Tese (Doutorado em Educação) - Programa de Pós-Graduação em Educação, Universidade Federal do Rio de Janeiro, 2010.

MIURA, R. K. K. Considerações sobre o Currículo Funcional Natural - CFN. In: OLIVEIRA, A. A. S.; OMOTE, S.; GIROTO, C. R. M. (Org.). Inclusão Escolar: as contribuiç̧ões da educação especial. São Paulo: Cultura Acadêmica, Marília: Fundepe, 2008. p. 153-165.

NUNES, D. Autismo e inclusão: entre realidade e mito. In: MENDES, E. G.; ALMEIDA, M. A. (Org.). Dimensões Pedagógicas nas práticas de inclusão escolar. 1. ed. Marília: Abpee, v. 2, p. 279-292, 2012.

NUNES, D.; LEMOS, J. P. Os desafios da inclusão no ensino regular: criança com autismo e características de hiperlexia. Revista Educação em Questão, v. 34, p. 63-80, 2009. 
PARRA, L. S. Atando laços e desatando nós: reflexões sobre a função do acompanhamento terapêutico na inclusão escolar de crianças autistas. 2009. 153 f. Dissertação (Mestrado em Psicologia Clínica e Cultura) - Universidade de Brasília, Brasília, 2009.

PEDROSA, E. R. M. Interações de crianças com deficiência no cotidiano escolar "inclusivo". Dissertação (Mestrado em Distúrbios do Desenvolvimento) - São Paulo: Universidade Presbiteriana Mackenzie, 2010. Disponível em: 〈http://tede.mackenzie.com.br//tde_busca/ arquivo.php?codArquivo=2070 . Acesso em: 14 abr. 2013.

PEREIRA, M. C. L. Pais de alunos autistas: relatos de expectativas, experiências e concepções em inclusão escolar. Mestrado. Universidade Católica de Brasília - Psicologia. v. 1, p. 162, 2009.

PRESTES, M. A. Diagnóstico de autismo na rede pública de ensino do DF: um estudo exploratório da situação atual. Dissertação (Mestrado em Educação) - Universidade Católica de Brasília, 2009.

RAHME, M. M. F. Laço social e educação: um estudo sobre os efeitos do encontro com o outro no contexto escolar. 2010. Tese (Doutorado em Educação) - Faculdade de Educação, University of São Paulo, São Paulo, 2010.

SANTOS, M. A. Entre o familiar e o estranho: representações sociais de professores sobre o autismo infantil. Dissertação (Mestrado em Psicologia) - Universidade Federal de Pernambuco, 2009.

SCHMIDT, C. Temple Grandin e o autismo: uma análise do filme. Revista Brasileira de Educação Especial, Marília, v. 18, n. 2, 2012, p. 179-194. Disponível em: 〈http://www.scielo.br/ pdf/rbee/vl8n2/vl8n2a02.pdf>. Acesso em: 27 maio 2013.

SMITH, D. D. Transtornos do Espectro Autístico. In: SMITH, D. D. Introdução à Educação Especial: ensinar em tempos de inclusão. São Paulo: Artmed, 2008. p. 355-377.

SERRA, D. Entre a esperança e o limite: um estudo sobre a inclusão de alunos com autismo em classes regulares. Rio de Janeiro, 2008. 124p. (Tese de Doutorado) - Departamento de Psicologia, Pontifícia Universidade Católica do Rio de Janeiro.

SIMPSON, R. Evidence-based practices and students with autism spectrum disorders. Focus on Autism and Other Developmental Disabilities, v. 20, n. 3, p. 140-14, 2005.

SUPLINO, M. Vivências inclusivas de alunos com autismo. Rio de Janeiro: Kirios, 2009.

VALLE, M. H. F.; GUEDES, T. R. Habilidades e competências do professor frente à inclusão. In: NUNES SOBRINHO, F.P. (Org.). Inclusão educacional - pesquisa e interfaces. Rio de Janeiro: Livre Expressão, 2003.

VITALIANO, C. R.; VALENTE, S. M. P. A formação de professores reflexivos como condição necessária para inclusão de alunos com necessidades educacionais especiais. In: VITALIANO, C. R. Formação de professores para a inclusão de alunos com necessidades educacionais especiais. Londrina: EDUEL, p. 31-48, 2010. 


\section{Notas}

${ }^{1}$ A Escola Parque apresenta concepção acadêmica distinta da escola regular, tendo como função complementar a matriz pedagógica da classe comum. O currículo é constituído por disciplinas de Artes e Educação Física. O corpo docente é formado por professores do ensino regular e especialistas em Educação Especial. O aluno frequenta essa escola uma vez por semana, no contraturno.

${ }^{2}$ O CFN fundamenta-se numa filosofia de educação que determina a forma e o conteúdo de um currículo adequado às características individuais. Requer uma metodologia instrucional que enfatiza a aplicação do conhecimento e das habilidades em contexto real (MIURA, 2008, p. 155)

${ }^{3}$ Trata-se de um instrumento formal, de caráter informativo e orientador, que tem como propósito subsidiar o trabalho do docente. Ele fornece informações diversificadas, desde características do contexto familiar do aluno até os procedimentos educacionais a serem adotados na elaboração de seu plano educacional.

\section{Correspondência}

Debora Regina de Paula Nunes - Universidade Federal do Rio Grande do Norte, Centro de Educação Sala 1, Lagoa Nova, CEP: 59072-970 - Natal, Rio Grande do Norte - Brasil.

E-mail: deboranunes@ufrnet.br - carlopsico@gmail.com

Recebido em 29 de maio de 2013

Aprovado em 22 de junho de 2013 